\title{
NEST ATTENDANCE OF SOUTHERN GIANT PETREL (Macronectes giganteus) ON ELEPHANT ISLAND
}

\author{
http://dx.doi.org/10.4322/apa.2014.032 \\ Uwe Horst Schulz ${ }^{1, *}$, Lucas Krüger ${ }^{1}$, Maria Virginia Petry ${ }^{1}$ \\ ${ }^{1}$ Universidade do Vale do Rio Sinos -UNISINOS, São Leopoldo, Rio Grande do Sul, Brazil \\ *e-mail: uwe@unisinos.br
}

\begin{abstract}
According to expressive size dimorphism between Southern Giant Petrel genders, differences in foraging and nest attendance are expected between female and male petrels. This study aims to investigate differences in nest attendance duration and frequency. 14 Adults were tagged with radio-transmitters, seven females and seven males, of which five were breeding pairs, in Stinker Point, Elephant Island. The radio signals were registered by an Automatic Listening Station between December 2009 and February 2010. Females attend more often the nest than males (binominal test, $C h i^{2}=799.3 ; P<0.001$ ), although the mean number of days each gender attended the nest was not different $(F=0.01 ; P=0.92)$. Our results suggest a higher breeding effort in females while larger males may trade off reproduction success in favor of own survival, at least in anomalous summers. Under severe climatic conditions like the austral summer of 2009/2011 males tend to abandon the nest earlier than females.
\end{abstract}

Keywords: behavior, nesting, radio-transmitters, telemetry

\section{Introduction}

The Southern Giant Petrel (Macronectes giganteus) is a circumpolar cold-water seabird of the southern oceans and the Antarctic (Onley \& Scofield, 2007). It is a long-lived species that undertakes long-distance migrations between the breeding periods (Harrison, 1983). The breeding period is a key element in the bird's lifecycle. Several studies focus on the behavior of the parents during the breeding process. In species with sex size dimorphism differences in provision frequency and duration of foraging trips between genders can be expected. Gender related differences in foraging behavior were reported for several albatross species (Weimerskirch et al., 1993; Phillips et al., 2004). Size differences between female and male giant albatrosses are expressive. Males are up to $20 \%$ heavier than females (Gonzáles-Sólis et al., 2000a) and sex related differences in foraging duration and frequency can be expected. Studies of Gonzáles-Sólis et al. (2000a,b) and Gonzáles-Sólis (2004) concentrated particularly on Northern Giant Petrel
(Macronectes halli). They found substantial segregation between males and females in relation to foraging strategies, foraging areas and feeding resources. Males made shorter trips than females, principally feeding on penguin and seal carrion on the beaches close to the breeding sites. Females were encountered more frequently in pelagic habitats than males and fed more often on marine prey. Gonzáles-Solís et al. (2002) reported two types of trips by satellite tracking in Giant Petrels: pelagic with mean duration of 15 days and coastal trips of median durations of eight days. Unfortunately, the author's do not differentiate results nor for species neither for genders. The objectives of our study were a) to perform a radio tagging pilot study to test the deployment of unattended Automatic Listening Stations (ALS) in a pilot study on Elephant Island and b) investigate sex related differences in nest attendance during the breeding period of Giant Southern Petrel and to describe presence / absence patterns of both sexes. 


\section{Materials and Methods}

\section{Study area}

The tagging experiment was conducted at Stinker point on Elephant Island, South Shetland Islands (Figure 1). 95\% of the island is under permanent ice cover. All colonies of seabirds are concentrated on the remaining $5 \%$ which may be ice free at late Antarctic summer. Mean annual temperature is $-2{ }^{\circ} \mathrm{C}$, mean summer temperature $1{ }^{\circ} \mathrm{C}$ (Instituto Hidrografico de la Armada Chile, 1989). Even in the austral summer snowstorms and low visibility due to fog are frequent.

\section{Tagging}

For tagging digitally coded transmitters (LOTEK; type MCTF-3A weight $16 \mathrm{~g}, 149 \mathrm{MHz}$ ) were used. Burst rate was set to $5 \mathrm{~s}$, expected transmitter life $641 \mathrm{~d}$. Tagging procedure extended 7 days, due to the weather conditions with temperatures at $-5{ }^{\circ} \mathrm{C}$ and gust winds of up to 35 miles $\mathrm{h}^{-1}$. We tagged seven females and seven males on nine nests, of which five were occupied by couples (Table 1 ).

All individuals were tagged when sitting on the nest. One leg was gently extended without securing the body of the bird. The transmitter, glued on a piece of soft foam, was attached to the tarsus-metatarsus by $3 \mathrm{M}$ Silver tape, the whip antenna extending in the direction of the foot (Figure 2). Some individuals, mostly males, had to be secured holding the body. When these individuals were released after tagging, they escaped flying. Usually they returned to nest in less than two minutes.

The radio signals were registered by an Automatic Listening Station (ALS) which consisted of a SRX 400

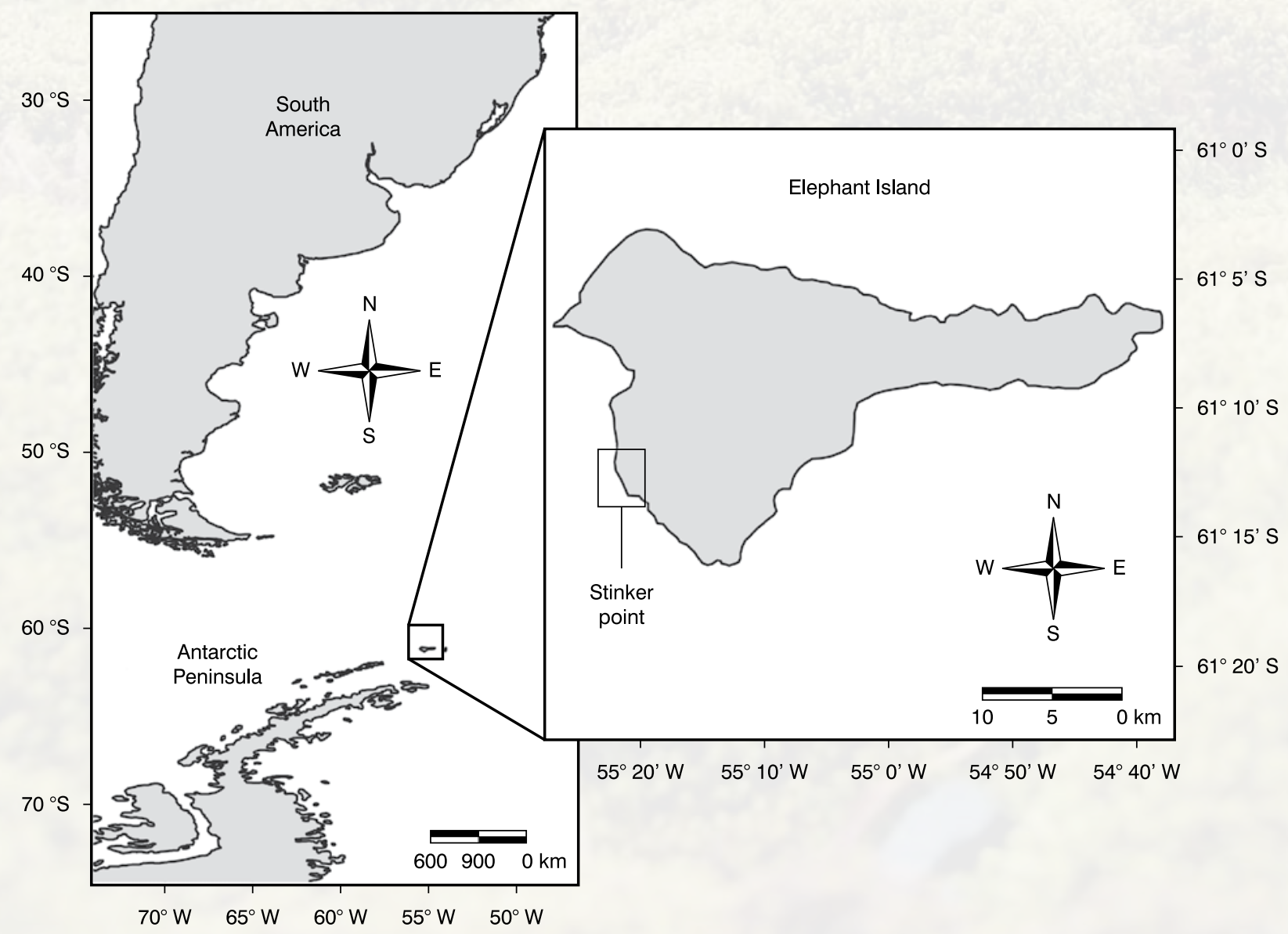

Figure 1. Antarctic Elephant Island. The rectangle indicates the study area at Stinker Point. 
Table 1. Tagging date, digital transmitter code, gender and nest number of tagged individuals. Note that nest number 1, 3, 5 and 14 were occupied by one tagged parent only.

\begin{tabular}{cccccc} 
Date & Hour & Code & Female & Male & Nest \\
\hline 04-DEC-09 & 11.00 & 102 & & $X$ & 1 \\
04-DEC-09 & 11.00 & 103 & $X$ & & 3 \\
04-DEC-98 & 12.00 & 105 & & $X$ & 5 \\
06-DEC-09 & 10.00 & 114 & $X$ & & 14 \\
04-DEC-09 & 11.00 & 101 & & $X$ & 2 \\
05-DEC-09 & 12.00 & 104 & $X$ & & 2 \\
03-DEC-09 & 16.00 & 107 & $X$ & & 7 \\
05-DEC-09 & 12.00 & 106 & & $X$ & 7 \\
03-DEC-09 & 16.00 & 108 & $X$ & & 8 \\
05-DEC-09 & 12.00 & 109 & & $X$ & 8 \\
03-DEC-09 & 16.00 & 110 & $X$ & & 10 \\
04-DEC-09 & 12.00 & 112 & & $X$ & 10 \\
06-DEC-09 & 10.00 & 111 & & $X$ & 11 \\
09-DEC-09 & 11.00 & 113 & $X$ & & 11 \\
\hline
\end{tabular}

receiver with data logger function (LOTEK, Canada) equipped with a standard omnidirectional whip antenna. Time partition was set to 30 minutes to optimize data logger memory capacity of 524288 bytes. The power was supplied by the internal batteries of the receiver, which were automatically recharged in a 12 hours rhythm by the electric generator of the research unit. Birds were tagged in two different breeding groups at $170 \mathrm{~m}$ distance to the receiver. The tracking period extended from 03 December 2009 to 10 February 2010. Between 07 January and 10 February the equipment was left unattended. During this period power was supplied by a $300 \mathrm{Ah}$ truck battery. Data from the ALS was downloaded in three days intervals. During the absence of the research team data accumulated for approximately one month in the internal receiver memory. When necessary data were ln-transformed to meet the criteria of homogeneity of variances for ANOVA, tested by Levene's statistic. Binominal test was used to test for differences in presence data between genders. Significance level in all tests was set to $\mathrm{P}<0.05$. The dispersion measure is the standard error (s.e.).

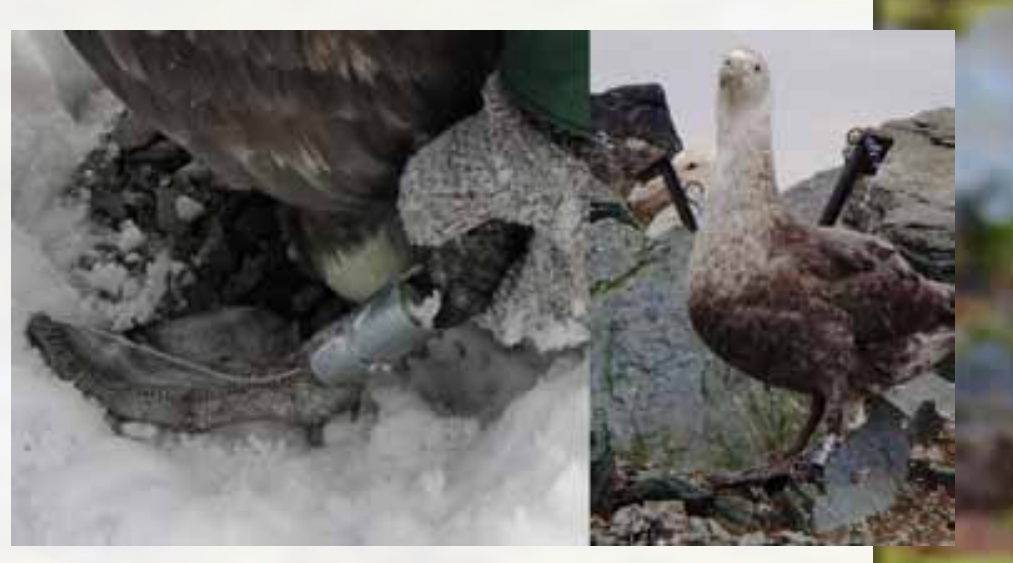

Figure 2. Leg mounted radiotransmitters on Southern Giant Petrel.

\section{Results}

During the three month period of tracking two technical problems occurred. The first was power supply, which accidentally disconnected and caused a data loss of two days. The second was related to false absence data. On several occasions the presence of a tagged bird was confirmed by visual observation but the ALS did not receive the signal. All tagged individuals remained in the study area and their signals were registered throughout the investigation period (Figure 3). A total of 8086 events of radio signals were registered by the ALS, of which 5314 were produced by the presence of females and 2772 by males. This difference in presence of both genders is highly significant (multinominal test, $\mathrm{Chi}^{2}=799.3 ; \mathrm{P}<0.001$ ). Of all 14 tagged petrels 11 resumed breeding activities after tagging. Three individuals did not: a male without tagged partner (nest 1) and a couple (nest 11). The breeding individuals produced distinct presence/absence patterns (Figure 3, Table 1). Although females were present during 18 periods (min. 3 days, max. 9 days) and males only 5 periods (min. 2, max. 13 days) mean nest attendance (females 6.4 days \pm 0.56 ; males $6.8 \pm 1.3$ ) was not significantly different in both sexes $(\mathrm{F}=0.01 ; \mathrm{P}=0.92)$. All nests were abandoned during the study period. The first was nest 8 on 18 December, the last nest 10 on 23 January. The attendance pattern of codes 110 (female) and 112 (male; Figure 3) show, that the male ceases breeding on 27 December. At this date occurred a switch in nest attendance. The departing male was registered 


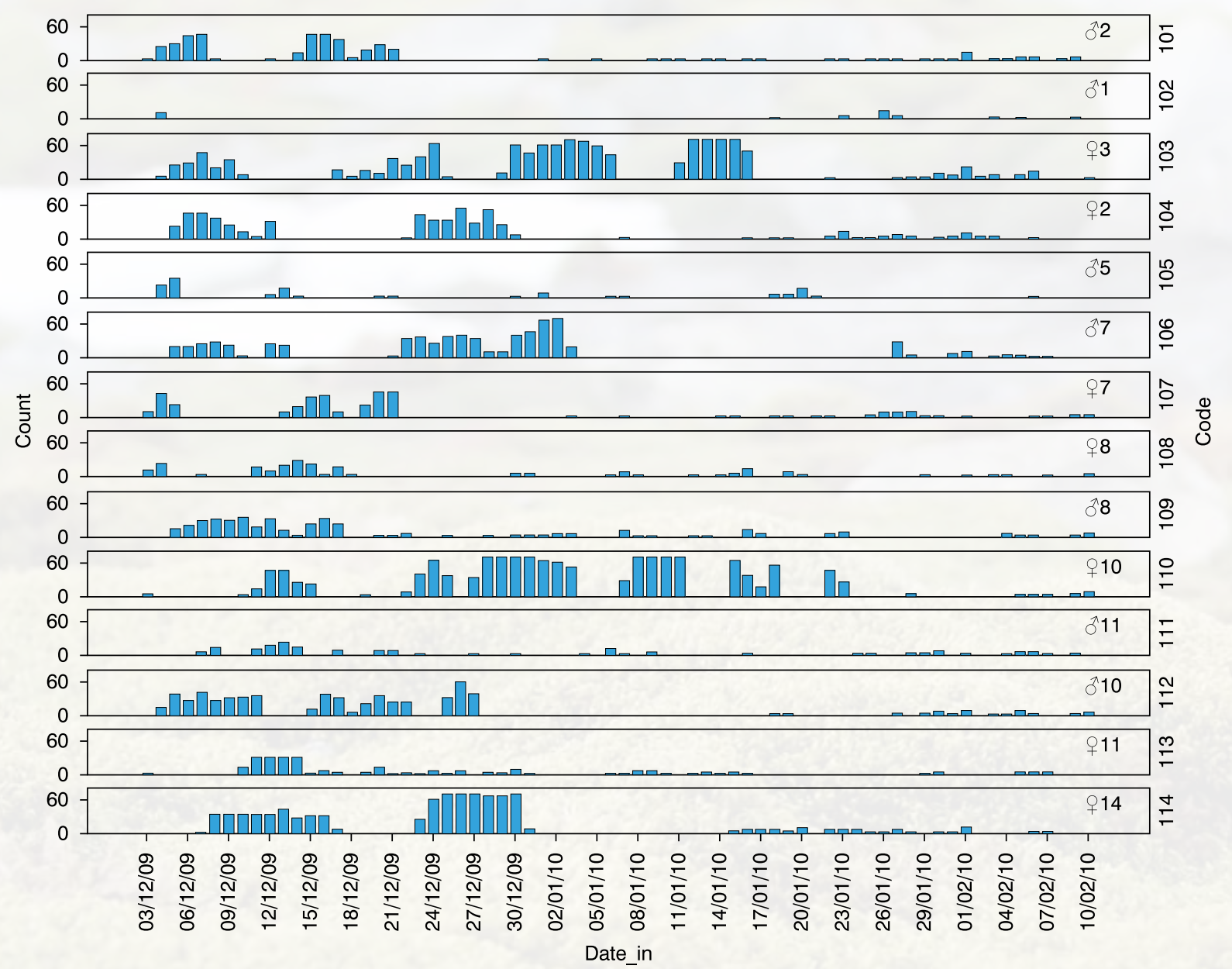

Figure 3. Nest attendance periods of tagged Giant Southern Petrel. Codes on the left refer to individuals of Table 1. Numbers on the left inside the figure refer to nests.

the last time at 12.30 hours and the arriving female at 12.36 hours. Since then the female remained for a period of eight days on the nest and left for four. She left and returned three times, with decreasing periods of nest attendance until the nest was abandoned ultimately on 23 January.

\section{Discussion}

The results of our study showed, that the deployment of unattended ALS is technically viable under the severe climatic conditions of Elephant Island. Signal reception problems may be reduced in future experiments by the use of directional antennas. Tagging data revealed that the signal count of tagged females is significantly higher than for males. This means, that female Petrel presence in the breeding colony is far more intensive. The higher number of uninterrupted attendance periods (18) reinforces this result, although mean attendance duration did not differ from males. These results indicate a higher breeding effort in females while larger males may trade off reproduction success effort in favor of own survival (Bijleveld \& Mullers, 2009). Adult survival is a principal demographic parameter that drives the population dynamics in long-lived seabirds (Rolland et al., 2009). Further tagging experiments, which are planned for the season 2011/2012 have to confirm the present tendency on a broader data base. De Villiers et al. (2006) documented high stress levels in congeneric Northern Giant Petrel when disturbed. This stress sensitivity may have caused the interruption of the breeding process in three individuals as consequence of the tagging procedure. 
All other individuals initially continued breeding and abandoned the nests later. No chick hatched in nests where one or both parents were tagged. Most probably the unusual extreme weather conditions of the 2009/2010 austral summer caused the reproduction failures. Heavy snow precipitation and gust winds of $90 \mathrm{~km} \mathrm{~h}^{-1}$ occurred frequently at the beginning of the tracking period. Snow cover extended until mid December. When the research team returned on 13 February, census data showed, that only $5.8 \%$ of pairs successfully raised a fledge.

\section{Conclusions}

The deployment of unattended ALS is technically viable for a period of up to five weeks. Three out of 14 individuals abandoned their nests probably as consequence of tagging stress. During the tracking period, female Giant Petrel displayed a higher breeding effort than males. Under severe climatic conditions like the austral summer of 2009/2011 males tended to abandon the nest earlier than females.

\section{Acknoledgements}

The study had financial support from INCT-APA (CNPq Process $n^{\circ}$ 574018/2008-5), FAPERJ (E-26/170.023/2008), WCS (Wildlife Conservation Society) and supported by the Ministry of Environment, Ministry of Science and Technology and the Secretary of Marine Resources (SECIRM).

\section{References}

Bijleveld, A.I. \& Mullers, R.H.E. (2009). Reproductive effort in biparental care: an experimental study in long lived Cape gannets. Behavioral Ecology, 20(4): 736-44

De Villiers, M.; Bause, M.; Giese, M. \& Fourie, A. (2006). Hardly hard-hearted: heart rate responses of incubating Northern Giant Petrels (Macronectes halli) to human disturbance on sub-Antarctic Marion Island. Polar Biology, 29(8): 717-20.

Gonzáles-Solís, J.; Croxall, J.P. \& Wood, A.G. (2000a). Sexual dimorphism and sexual segregation in foraging strategies of northern giant petrels Macronectes halli during incubation. Oikos, 90: 390-98.

Gonzáles-Solís, J.; Croxall, J.P. \& Wood, A.G. (2000b). Foraging partitioning between giant petrels Macronectes spp. And its relationship with breeding population changes at Bird Island, South Georgia. Marine Ecology Progress Series, 204: 279-88

Gonzáles-Solís, J.; Croxall, J. P. \& Briggs, D. R. (2002). Activity patterns of giant petrels, Macronectes spp., using different foraging strategies. Marine Biology, 140: 197-204.

Gonzáles-Sólis, J. (2004). Sexual sixe dimorphism in northern giant petrels: ecological correlates and scaling. Oikos, 105: 247-54.

Harrison, P. (1983). Seabirds, an identification guide. Boston: Houghton Mifflin.

Instituto Hidrografico de la Armada Chile. (1989). Derrotero de la costa de Chile. 2 ed. Santiago, I.H.A pub. 3006, v. 6, 251 pages.

Onley, D. \& Scofield, P. (2007). Albatrosses, petrels and shearwaters of the world. New Jersey: Princeton University Press.

Phillips, R. A.; Silk, J. R. D.; Phalan, B.; Catry, P. \& Croxall, J. P. (2004). Seasonal sexual segregation in two Thallassarche albatross species: competitive exclusion, reproductive role specialization or foraging niche divergence. Proceedings of the Royal Society of London - Series B - Biological Science, 271: 1283-91.

Rolland, V.; Novoux, M.; Barbraud, C. \& Weimerskirch, H. (2009). Respective impact of climate and fisheries on the growth of an Albatross population. Ecological Applications, 19: 1336-46.

Weimerskirch, H.; Salamolard, M.; Sarrazin, F. \& Jouventin, P. (1993). Foraging strategy of wandering albatrosses through the breeding season: a study using satellite telemetry. Auk, 110: 325-42. 